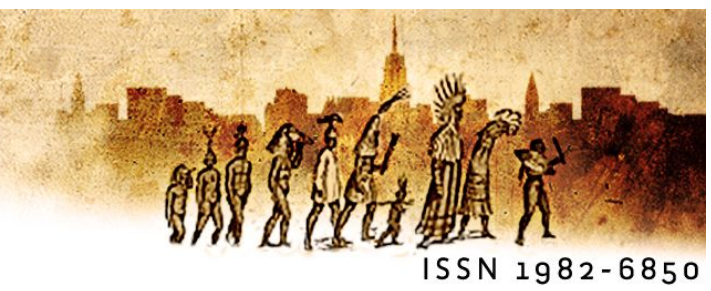

\title{
Um retrato da formação inicial de professores de línguas: duas cenas
}

"Não, o ensino não é um sacerdócio, mas um verdadeiro
trabalho; não, os professores não são "iluminados", dotados
de um hipotético "dom"; ao contrário são trabalhadores que
têm, como os outros, de aprender seu "métier", de adquirir
experiência sobre ele e, assim tornarem-se profissionais
cada vez mais."

(Jean-Paul Bronckart, 2009, p.162)

\author{
Fatiha Dechicha Parahybai (UFPE) \\ Eulália Leurquinii (UFC)
}

\begin{abstract}
Resumo: Neste artigo, nosso objetivo é ressaltar a relevância da formação inicial do professor de inglês língua estrangeira e de português língua materna, com base em dados de pesquisas realizadas em duas universidades públicas. Interessou-nos investigar como os estudantes em formação inicial verbalizaram por escrito seus saberes acerca da docência (VANHULLE, 2009, HOFSTETTER e SCHNEUWLY, 2009) e como a produção escrita foi vivenciada por eles. O objeto de pesquisa foi, por um lado, o ensino e aprendizagem da produção escrita do gênero acadêmico, e por outro lado, a formação inicial do estudante semiotizada no gênero acadêmico. Com base nos pressupostos teóricos de análise textual (BRONCKART, 1999), estudamos relatórios de estágios, monografias, assim como diários reflexivos e autocomentários, focando o conteúdo temático, os mecanismos de textualização e os enunciativos. Os resultados revelaram que o aluno, na fase final de sua formação inicial, apresenta dificuldades na produção escrita dos gêneros analisados. Da mesma forma, ficou evidente que não há uma reflexão sobre o seu agir docente, mas apenas descrições de cenas conflitantes vivenciadas. Isso também nos leva a questionar o perfil do futuro professor de línguas.
\end{abstract}

Palavras chave: formação de professor, ensino e aprendizagem, escrita.

Résumé: Dans cet article, notre objectif consiste à soulever l'importance de la formation initiale des enseignants $d$ 'anglais langue étrangère et de Portugais langue première ; sur la base de recherches réalisées au sein de deux universités publiques. Cette étude consiste à examiner comment les étudiants en formation initiale expriment par écrit leurs savoirs relatifs à la profession enseignante (VANHULLE, 2009, HOFSTETTER et SCHNEUWLY, 2009) et comment ils perçoivent leur vécu de la production écrite. L'objet de recherche porte d'une part sur l'enseignement et l'apprentissage de la 
production écrite du genre académique et, d'autre part, sur la formation initiale sémiotisée dans le texte académique. Prenant comme base les présupposés théoriques de l'analyse textuelle (BRONCKART, 1999), nous avons examiné les rapports de stage, les mémoires de fin d'études ainsi que les journaux et auto-commentaires, en nous concentrant particulièrement sur le contenu thématique, les mécanismes de textualisation et énonciatifs. Les résultats ont révélé que l'étudiant, qui se trouve en phase finale de formation initiale, a des difficultés de production écrite des genres analysés. De la même façon, il apparaît comme évident qu'il n'y a pas de réflexion sur l'agir enseignant, ce sont plutôt des descriptions de scènes conflictuelles vécues. Cela nous mène à interroger le profil du futur enseignant de langues.

Mots-clés: formation des enseignants, enseignement et apprentissage, production écrite.

\section{Introdução}

A partir de duas pesquisas, realizadas em duas instituições públicas em estados brasileiros diferentes, objetivamos mostrar perspectivas distintas de uma questão comum: a formação inicial de professores de línguas. Com isso, apresentamos duas cenas da escrita do gênero acadêmico produzido ao final do Curso de Letras. Em uma, destacamos o processo de ensino e aprendizagem da produção escrita de uma monografia e a reflexão sobre a produção escrita por meio de um diário. Na outra, salientamos a vivência da prática docente por meio dos relatórios de estágio e do autocomentário sobre a realidade do estágio.

Interessa-nos investigar como os alunos em formação inicial verbalizam por escrito seus saberes acerca da docência e a sua vivência. Interessa-nos igualmente saber como a produção escrita é vivenciada por eles e se o tema ensino e aprendizagem da produção escrita é verbalizado em seus textos e, caso seja, analisar a maneira como isso ocorre. Salientamos que, no contexto da formação inicial do professor de língua estrangeira e de língua materna, o futuro profissional atua em dois mundos representados, pois deve saber usar a língua e saber ensiná-la. Assim, buscamos evidenciar os pontos comuns, que nos proporcionem uma discussão sobre a relevância da formação inicial. No contexto delimitado, neste artigo, nosso enfoque é o curso de Letras-Licenciatura Inglês da Universidade Federal de Pernambuco e o Curso de Letras Vernáculas da Universidade Federal do Ceará. Na primeira instituição, focalizamos duas disciplinas: Compreensão e Produção de Texto em Língua Inglesa e Monografia. Na segunda instituição, nosso alvo é a disciplina Estágio de regência de língua portuguesa. 
Selecionamos a formação inicial como objeto de estudo porque entendemos que o final do Curso permite que tenhamos uma ideia clara sobre as capacidades do futuro professor de pôr em prática os saberes adquiridos no percurso da sua formação. A partir desse posicionamento, nosso enfoque consiste em verificar como o futuro professor age discursivamente, quer seja quando faz uma reflexão teórico-prática a partir de um problema analisado por ele próprio, quer seja quando descreve e analisa sua vivência de sala de aula.

Na monografia e no relatório de estágio, temos descrições e análises de cenas de sala de aula, isto é, de experiências de práticas didáticas vivenciadas pelos estudantes. Para a monografia, o aluno definiu um problema, estudou-o, analisou-o e apresentou resultados da pesquisa realizada. Para o relatório, ele deu aula, registrou suas vivências do estágio de regência e descreveu-as. Além da monografia, também desenvolveu uma reflexão sobre o processo da escrita em um diário no qual relata sua experiência da escrita e, além do relatório do estágio de regência, consideramos o autocomentário feito sobre o referido estágio.

Nesse artigo, elegemos três pontos a serem analisados nas produções: o conteúdo temático selecionado pelo estudante, os mecanismos de textualização (coesão verbal e nominal) e os mecanismos enunciativos (modalização). Com base nesses elementos, interpretamos situações problemáticas sobre o ensino e aprendizagem da produção escrita e sobre a formação inicial de professores elencadas pelos estudantes.

\section{Ensino e aprendizagem da produção escrita e sua interface com a formação inicial}

O ensino da produção escrita, como ação necessária nos diversos níveis de escolaridade, inclusive em nível universitário, em decorrência das dificuldades de aprendizagem, constitui um tema constante e recorrente, como mostram as pesquisas (SCHNEUWLY, 2008; DOLZ, et al., 2009/2010; ASSIS, 2014; PEREIRA e GRAÇA, 2015). Essa constatação nos remete de imediato à discussão de dois eixos interdependentes, a nosso ver, que são relacionados com a produção de textos escritos.

O primeiro eixo tem a ver com a própria questão da escrita, tanto no que diz respeito ao uso da língua, a depender das situações de comunicação, quanto no que tange ao papel do professor para o desenvolvimento das capacidades linguístico-discursivas dos aprendizes 
de escrita. Esse eixo centra-se na essencialidade do uso e do ensino da língua escrita e, por conseguinte, no papel fundamental da escola no processo de desenvolvimento do aprendiz, como mostram alguns autores, todos ancorados na teoria de Vygotski (PERRENOUD AEBI, 1997; SCHNEUWLY, 2008; FRIEDRICH, 2010). Para Vygotski (2009, p.290), o ensino tem um "papel decisivo" na tomada de consciência dos conceitos científicos e é essencial para o desenvolvimento dos alunos. Ademais, o autor defende que "o único bom ensino é aquele que precede o desenvolvimento ${ }^{1 \prime \prime}$ (VYGOTSKI, 1985). Esse postulado remete-nos à concepção de zona de desenvolvimento proximal, segundo a qual antes de iniciar uma ação de ensino, é necessário considerar as capacidades iniciais do aprendiz (DOLZ et al., 2009/2010), ou seja, o seu desenvolvimento atual. Assim, o ensino estimula e dá origem a uma série de processos internos de desenvolvimento. Em suma, o pensamento de Vygotski salienta a interdependência existente entre aprendizagem e desenvolvimento.

Ao conceber dois tipos de desenvolvimento, 'desenvolvimento sociohistórico' e 'desenvolvimento natural', Bronckart (2013) mostra que o desenvolvimento é possível independentemente da condição biológica, contanto que haja ensino. Dessa maneira, salientamos o papel da escola e da formação, na medida em que "o meio constitui a fonte de desenvolvimento" (FRIEDRICH et al., 2013, p. 23). Do ponto de vista da aprendizagem, entendemos que a escola constitui uma condição essencial para que haja transformação qualitativa. Em suma, sobressai a preocupação para com o sujeito-aprendiz e com seu potencial em desenvolver-se mediante a linguagem e desenvolver igualmente sua capacidade de usá-la.

Na produção escrita de um gênero da esfera acadêmica, há de se considerar o estilo, a forma e o conteúdo. Ao ressaltarmos a forma, observamos que sobressaiu, tanto nas monografias quanto nos relatórios, problemas no âmbito das "relações de dependência entre argumentos que compartilham uma ou várias propriedades, referenciais", isto é, no âmbito da coesão nominal. Da mesma forma observamos que houve problema na "explicitação das relações de continuidade e/ou descontinuidade de oposição existente entre os elementos de significação expressos pelos sintagmas verbais, ou pela coesão verbal" (BRONCKART, 1999, p. 273).

\footnotetext{
1 "le seul bon enseignement est celui qui précède le développement"
} 
Escrevemos porque temos algo a dizer a alguém. Nesse agir de linguagem, o conteúdo temático tem um papel fundamental, pois ele é justamente o conjunto das informações explicitamente apresentadas no texto. Para apresentá-las, o autor, em função do contexto de produção, assume papeis e modaliza seu discurso em função dos seus propósitos.

O segundo eixo diz respeito à formação inicial do professor, assim como os aspectos relacionados com a qualificação profissional. Segundo Kleiman (2008, p. 17), esse tema é bastante discutido em trabalhos científicos a partir de três vertentes: pesquisas com foco nos "contextos naturais em que essa formação é realizada"; pesquisas com foco "no contexto onde essa formação é evidenciada (aulas de leitura, redação, gramática em diversos níveis e cursos)"; e pesquisas com foco em "diversas modalidades de construção de conhecimentos (aula de curso de licenciatura, diários introspectivos, pesquisas colaborativas, etc.) a fim de determinar como a identidade do professor é construída e contribuir para o ensino de línguas". Acrescentamos a essas vertentes outro elemento: a verbalização feita pelos estudantes em sessão de autoconfrontação, instrução ao sósia e grupo focal acerca dos saberes mobilizados em sala de aula. Esse elemento vem dando uma grande contribuição para que possamos ter acesso a informações não observáveis. Ademais, a verbalização possibilita que o professor reflita sobre seu agir em sala de aula, dando-lhe a oportunidade de ressignificá-lo.

Hofstetter e Schneuwly (2009, p. 17-18) apontam que há dois tipos de saberes que se relacionam com as 'profissões do ensino e da formação': os saberes a serem ensinados e os saberes para ensinar ${ }^{2}$. Os primeiros constituem os objetos de trabalho do professor, enquanto os últimos são as ferramentas de trabalho desse profissional. Tratando do contexto da formação inicial do professor, Vanhulle (2009) assegura que na sala de aula, o estagiário mobiliza saberes e que esses 'saberes de referência' servirão de fundamento para a formação docente de maneira a adquirir ou a fortalecer saberes e capacidades, reconhecidos socialmente e academicamente como elementos que constituem a docência. Aliado a isso, o professor também conta com os 'saberes práticos ${ }^{3}$. Com base nesse entendimento, podemos depreender que os saberes profissionais, adquiridos a partir de

\footnotetext{
2 "Savoir à enseigner et savoirs pour enseigner"

3 "savoirs de référence [...] [et] savoirs pratiques"
} 
referenciais acadêmicos e institucionais, constroem-se em conjunto com o trabalho e através da prática, que, por sua vez, vão propiciar outros saberes.

Na pesquisa desenvolvida na UFPE, por meio da monografia, constatamos lacunas que dizem respeito à mobilização de saberes para ensinar quando o foco consistia nos saberes a serem ensinados. Por sua vez, na pesquisa desenvolvida na UFC, através dos relatórios de estágio de regência, verificamos problemas no âmbito dos saberes a serem ensinados, quando o foco era os saberes para ensinar.

A distinção que se faz entre os saberes adquiridos e o uso deles nos remete ao conceito de 'transposição didática'. Esta consiste em todo "trabalho que, a partir de um objeto de saber a ensinar, faz um objeto de ensino4" (CHEVALLARD, 1991, p. 39). Tal ação requer uma transformação de um 'objeto de saber' em 'objeto a ensinar', que resulta em 'objeto de ensino'. Baseado na concepção de transposição didática, o saber científico é transformado em uma versão didática. Schneuwly (2009, p. 17) vê esse processo como "um elo de uma longa cadeia de transformações do saber para fins de ensino e de aprendizagem ${ }^{5 \prime}$. Esse autor defende que o 'objeto ensinado' é o resultado de uma incessante transformação que ocorre na interação didática entre professor e aluno.

Schneuwly (2009) vai mais além ao explicar que para apreender o 'objeto ensinado' no processo didático é necessário explicitar os dois elementos que definem a transposição didática. O primeiro consiste na delimitação e no reconhecimento de um objeto de saber como objeto de ensino, de forma a torná-lo ensinável. Para que isso aconteça, deve haver uma modelização didática. O segundo elemento está relacionado à mudança da função dos saberes gerada pelo contexto novo no qual esses saberes estão situados. Os saberes emanam sempre de um contexto social de uso e assumem uma função prática nesse mesmo contexto. Schneuwly (2009, p. 21) esclarece ainda que "na escola, [o objeto de saber] torna-se um objeto de ensino para ensinar e para aprender, sendo a escola precisamente definida por essa função ${ }^{6 \prime \prime}$.

No processo de ensino e aprendizagem da produção escrita, a interação entre professor e aluno não pode se restringir à identificação e seleção de saberes a serem ensinados. A interação pós-avaliação e o tutoramento são igualmente essenciais nesse

\footnotetext{
4 "Le travail qui d'un objet de savoir à enseigner fait un objet d'enseignement"

5 "Un maillon d'une longue chaîne de transformations du savoir à des fins d'enseignement et d'apprentissage"

6 "Il devient, à l'école, un objet d'enseignement à enseigner et à apprendre, l'école étant précisément définie par cette fonction"
} 
processo (PARAHYBA, 2009, 2010). O caráter imprescindível da avaliação formativa e da regulação no processo de ensino e de aprendizagem da produção escrita é enfatizado considerando que a resolução de problemas e dificuldades - a reescrita - "supõe uma reorganização dos conhecimentos e do funcionamento da escrita7" (DOLZ et al. 2009, p. 34). A reescrita ou reconstrução do texto, objeto ensinado, resultante de uma avaliação formativa e de regulação, permite ao aprendiz desenvolver sua capacidade de (re)construção do significado do objeto ensinado (SCHNEUWLY, 2009).

Na pesquisa desenvolvida na UFPE, cujo foco foi o ensino e a aprendizagem da escrita, realizamos avaliação formativa e a regulação da aprendizagem da escrita, através de sequências didáticas. Isso nos permitiu melhor perceber o processo da aprendizagem do estudante e intervir nele. Ao tratar de tal contexto, Allal (1999, p. 37) salienta o papel da interação professor-aluno, haja vista que "a regulação é co-construída no diálogo entre o aprendiz e o formador". Para isso, a autora chama nossa atenção para o fato de que as formas de intervenção em função das necessidades e dificuldades dos alunos ao longo da sequência didática requerem uma forte articulação das regulações ( $A L L A L, 2007)$. Em suma, o ensino da produção escrita, mediante sequências didáticas, será efetivo na condição de incorporar o trabalho de regulação na sequência.

Nesse momento, uma consideração importante a fazer é que em ambas as pesquisas a discussão sobre o gênero com os estudantes foi necessária. Na pesquisa cujo foco era o ensino e a aprendizagem da língua inglesa, o estudante produziu o gênero monografia na qual ele apresenta resultados de uma investigação sobre um tema relacionado à docência. Na pesquisa sobre a formação inicial de professor, o aluno descreve e interpreta o agir professoral e semiotiza sua experiência de estágio de regência no gênero relatório.

A opção pelo gênero textual decorre do fato de que, durante a formação inicial do futuro professor de língua materna e estrangeira, o estudante se comunica com textos de diversos gêneros. Ao mesmo tempo, ele também tem acesso a saberes sobre a língua estudada para que possa utilizá-la e ensiná-la em situações diversas. Com base nessa compreensão, esperamos, portanto, que, ao produzir a monografia, o diário de experiência de escrita ou o relatório de estágio, o aluno mobilize suas capacidades de linguagem.

\footnotetext{
7 "suppose une réorganisation des connaissances et du fonctionnement de l'écriture"
} 


\section{Contexto da ação formativa}

No contexto da UFPE, o aluno de língua inglesa deve desenvolver uma reflexão, conforme estabelece o regulamento, nos termos abaixo:

Artigo $4^{\circ}$ - O objeto de investigação deve estar relacionado a temáticas específicas da Licenciatura em Língua Inglesa.

Artigo $5^{\circ}$ - O TCC deve configurar-se como uma oportunidade para que os graduandos demonstrem aprofundamento temático, sejam estimulados à produção científica e à consulta de bibliografia especializada, aprimorem sua capacidade de interpretação e apliquem os conhecimentos construídos ao longo do curso.

A concepção de um documento prescritivo como esse pressupõe, em primeiro lugar, um letramento na língua estrangeira, ou seja, as capacidades de linguagem em inglês compatíveis com o nível da linguagem requerido para um gênero acadêmico. Segundo, pressupõe um letramento acadêmico. Noutros termos, requer saberes específicos sobre produção científica e marcos teórico-metodológicos relacionados com a formação do professor. Nesse sentido, surgem alguns questionamentos que orientaram a pesquisa: 1) 0 grau de apropriação da escrita em língua inglesa pelo aluno e suas capacidades linguísticodiscursivas determinam seu agir docente no futuro? 2) Quais saberes sobre o ensino e a aprendizagem da produção escrita fazem parte da formação inicial?

Considerando que os sujeitos implicados na ação de ensino são, ao mesmo tempo, aprendizes de produção escrita e aprendizes de professor, vimos uma oportunidade de investigar a possível relação da própria escrita com os saberes que eles têm sobre o ensino da produção escrita, sobretudo nos diários reflexivos.

No contexto da UFC, as disciplinas de estágio (Estágio em ensino de leitura, Estágio em ensino de oralidade e escrita, Estágio em ensino de análise linguística e Estágio de regência de língua portuguesa) se configuram como espaço por excelência para refletir a formação inicial do professor. Isso se dá pelo próprio perfil de cada uma dessas disciplinas.

Ao entender que, durante o estágio de regência, o estudante, pela primeira vez, vivencia a sala de aula no papel de professor da Educação Básica, fazemos os seguintes questionamentos: que conteúdos temáticos são considerados mais importantes pelos estagiários e por quê? Quais são as partes que compõem o gênero relatório e como nelas se estabelecem as relações de continuidade, descontinuidade ou oposições entre elementos de significação, em prol da coerência temática? 
Em ambas as pesquisas foi realizada uma análise interpretativa hermenêutica. Foram ao todo quinze monografias no contexto da UFPE e cinquenta relatórios no contexto da UFC. Neste artigo, utilizamos exemplos de quatro textos de cada instituição. Com efeito, a análise tomou como base os princípios de análise textual preconizados pelo Interacionismo Sociodiscursivo. Nesse sentido as categorias selecionadas foram os conteúdos temáticos, os mecanismos de textualização e os mecanismos enunciativos em função dos seguintes questionamentos: 1) que importância têm as coesões verbal e nominal na produção escrita do futuro professor de línguas? 2) quais saberes e conflitos emergem no conteúdo temático? 3) de que maneira o futuro professor se posiciona discursivamente?

\section{Os encaminhamentos da ação formativa}

Na pesquisa desenvolvida na UFPE, houve um ensino mediado pela professora, agindo na zona de desenvolvimento proximal, como veremos mais adiante. Além de a professora efetuar as devidas correções, ela possibilitou que os alunos fizessem uma reflexão sobre o uso da língua, mediando o processo da aprendizagem. Na pesquisa realizada na UFC, foram dadas as orientações sobre a produção dos relatórios e os estudantes leram artigos científicos sobre o assunto. A produção foi feita e entregue ao final da disciplina. No percurso da produção, nas reuniões de orientação, os alunos perguntavam sobre o gênero relatório quando necessário.

\subsection{Primeira cena}

O Programa de componente curricular proposto para a disciplina denominada "Compreensão e Produção de Texto em Língua Inglesa" prevê o ensino de gêneros textuais variados, entre os quais, o gênero artigo acadêmico. A disciplina é oferecida para alunos cursando o último período do curso de Letras - Licenciatura em Inglês da Universidade Federal de Pernambuco.

Haja vista que, no mesmo período, os alunos cursam outra disciplina ao final da qual devem apresentar as monografias de conclusão de curso, ocorreu uma discussão e negociação entre a professora-pesquisadora e os alunos para considerar o gênero monografia como objeto de ensino e de aprendizagem. A negociação decorreu da 
necessidade explicitada pelos alunos de aprender a produzir o referido gênero na língua inglesa, e pelo fato de a professora-pesquisadora ter feito uma avaliação prévia das capacidades de linguagem dos alunos na ocasião da elaboração dos projetos de pesquisa que deram origem às monografias.

Para esse propósito, foram elaboradas sequências didáticas para cada parte constitutiva do gênero monografia, objeto de ensino, que denominamos de 'mega' gênero. Foram, ao todo, seis sequências didáticas, a saber, resumo, introdução, fundamentação teórica, metodologia, análise e resultados, e conclusão. Dessa maneira, a cada sequência, os alunos foram envolvidos em atividades de reconhecimento das propriedades de cada seção, mediante análise comparativa com monografias e dissertações de mestrado do acervo da biblioteca do Centro, da universidade em questão.

Na sequência, produziram a versão inicial relativa à seção objeto de ensino e assim sucessivamente. Após a avaliação de cada componente do gênero monografia, o trabalho de regulação e de tutoramento era iniciado entre aluno e professor de forma a auxiliar o aluno a revisar, repensar e reescrever seu texto, ou seja, a versão final de cada seção da monografia. Esse procedimento foi repetido em todas as etapas até a versão preliminar. Todo esse processo foi concluído na ocasião da submissão da monografia, após um período de quatro meses.

Paralelamente, logo no início do trabalho com o objeto de ensino, o gênero monografia, os alunos foram solicitados a escrever um diário reflexivo, com base na orientação de fazer um relato sobre todo o processo de ensino e de aprendizagem da produção escrita do gênero, objeto de ensino. Vimos nesse dispositivo uma oportunidade para o aprendiz verbalizar sobre: a) ações de ensino e de aprendizagem de produção escrita em língua inglesa durante o curso de graduação, no âmbito da universidade; b) suas experiências como sujeitos aprendizes de escrita; c) suas avaliações sobre a própria capacidade de escrever nessa língua; d) suas representações acerca da escrita e; e) saberes explícitos tanto em relação à produção escrita quanto à formação docente para o ensino da produção de textos escritos. O roteiro indicativo segue abaixo: 
$\checkmark$ Refletir sobre o que aprenderam ou não aprenderam;

$\checkmark$ Como se sentem atualmente em relação à escrita do gênero monografia (artigo acadêmico);

$\checkmark$ Comparar o saber adquirido sobre a escrita desse gênero com a escrita da monografia em si;

$\checkmark$ Que tipo de saberes adquiriram sobre a produção escrita em inglês ao longo das disciplinas que tratam da formação docente;

$\checkmark$ Refletir sobre o ensino e a aprendizagem da produção escrita em inglês ao longo do curso de LetrasInglês;

$\checkmark$ Como se sentem em relação ao ensino da produção escrita e a docência no futuro.

No total, havia 19 alunos inscritos na disciplina, dos quais 12 eram mulheres e 7 eram homens e todos eram aprendizes de professor de língua inglesa. Algumas monografias foram elaboradas em dupla, conforme permite o regimento. Contudo, as monografias analisadas no presente artigo foram escritas individualmente.

\subsection{Segunda cena}

A pesquisa realizada na Universidade Federal do Ceará aconteceu na disciplina de regência de língua portuguesa. Teve como cenário salas de aula de escolas públicas situadas em Fortaleza, nos ensinos fundamental e médio. Os estagiários realizaram seu trabalho em dupla e da mesma forma eles produziram o relatório. Enquanto um estudante ministrava a sua aula, o outro a observava e fazia anotações. Durante o estágio, houve troca de papeis de maneira a assegurar que ambos os alunos pudessem realizar as duas etapas do estágio de regência. O objetivo do trabalho em dupla é identificar se as estratégias do planejamento feito por eles deram resultados positivos.

A etapa inicial do estágio acontece na universidade. Nessa etapa foram estudados temas teóricos importantes e houve orientações sobre a produção dos planejamentos das aulas e do relatório. Ainda na UFC, demos orientações para a seleção da escola da Educação Básica e também para a chegada do estagiário. O estudante foi orientado a registrar as observações sobre a comunidade, a escola e o material utilizado. Mostramos a importância de fazer descrições sobre a localização da escola, a clientela, os projetos desenvolvidos, a biblioteca e demais espaços de ensino e aprendizagem, a interação em sala de aula, o material didático, a transposição didática e demais itens considerados como relevantes.

Orientamos no sentido de os estudantes entregarem a sua Carta de apresentação e de participarem da reunião com o professor e o coordenador de língua portuguesa a fim de preparar o seu Plano de Estágio. Toda essas orientações e planejamentos são fundamentais 
para a preparação do relatório de estágio porque dentro do contexto da formação inicial, vemos o relatório como um espaço de descrição e interpretação das representações que os estagiários fazem da sala de aula e do seu agir.

Esperamos, portanto, que o estudante contemple todas as etapas do gênero em questão. Por essa razão, orientamos para que o relatório tenha a Capa, onde estão as informações necessárias para entendermos o contexto de produção; a introdução, onde se encontram o tema, os objetivos e também a apresentação das partes que compõem o desenvolvimento; o desenvolvimento, onde se encontram as descrições e interpretações das cenas selecionadas pelos estagiários; a conclusão, onde além de apresentar as considerações finais também apresentam (ou deveriam apresentar) encaminhamentos para posteriores reflexões; a bibliografia, onde se encontram as obras pesquisadas e referendadas e os anexos, quando necessário, onde estão os planos das aulas, os textos utilizados etc.

Organizamos o estágio de forma a considerar suas três etapas: antes, durante e depois da ida à escola. Cada uma possui suas particularidades e, em função delas, atividades são realizadas. Essas atividades têm como referência o planejamento das aulas e as orientações sobre as aulas ministradas.

A primeira etapa compreende as orientações para o estudante procurar e selecionar a escola. Antes, fizemos uma sessão de grupo focal a fim de termos acesso a informações sobre o que o estudante espera do estágio, se ele já tem experiência de sala de aula, por que ele optou pelo curso, entre outras questões. Nessa etapa, também foi realizada uma sessão de instrução ao sósia (neste caso, consideramos os estudantes que já são professores e os que não têm experiência ainda). A segunda etapa foi referente ao momento da escola. Ela compreende a chegada do aluno na escola até o término do estágio. A terceira etapa correspondeu ao término do estágio, ao retorno à universidade. Ao chegar à UFC, fizemos outra sessão de grupo focal a fim de rever os posicionamentos dos estudantes anteriores à sua ida à escola. Também realizamos autoconfrontações. Nelas, oralmente, o estudante foi motivado a explicar, descrever e interpretar situações a partir de cenas de sala de aula.

A produção do relatório aconteceu durante as três etapas. Nele, o estudante recuperou em sua memória as representações que fez das aulas ministradas, descreveu-as de forma resumida aquelas que mais the chamaram a atenção e interpretou-as. Embora sejam ainda pouco contempladas, entendemos que é revelador o fato de se considerar 
como pertinentes as etapas antes e após o estágio, uma vez que elas mostram tanto planejamentos quanto avaliações.

\section{Por dentro das cenas: resultados sobressalientes}

\section{Das monografias}

A monografia configura-se como espaço e oportunidade para pôr em prática os saberes de referência, construídos ao longo do curso de Licenciatura, ou seja, representa o momento de passar da esfera dos saberes teóricos para a esfera dos saberes práticos. Em virtude desse pressuposto, a título de ilustração, apresentamos um achado relativo a essa temática. Para isso, selecionamos um trabalho cujo tema foi a produção escrita de resenhas em língua inglesa ${ }^{8}$, que demonstra a efetiva apropriação do saber pelas alunas e como foi posto em prática.

O trabalho teve como objetivo discutir a importância do ensino da produção escrita do gênero resenha de obras literárias em inglês mediante sequência didática. A monografia evidencia a transposição didática dos saberes a ensinar, ou seja, os saberes de referência que as alunas efetivaram na própria pesquisa. Os saberes sobre a produção de gêneros textuais, sequências didáticas, que foram mobilizados pelas alunas, estão bem explícitos no texto. Na sua pesquisa, Alessandra e Eduarda elegeram um 'objeto de ensino' e o transformaram em 'objeto ensinado'. Ao mesmo tempo, ao eleger a zona de desenvolvimento proximal de seus alunos de língua inglesa, as professoras proporcionaram o desenvolvimento dos aprendizes.

\section{Conteúdos temáticos}

Os temas pesquisados pelos estudantes foram bastante variados. Convém salientar que as monografias tiveram como objeto de pesquisa tanto o agir professoral em sala de aula quanto ações de ensino. Para efeito de ilustração, citaremos alguns: o uso de gêneros como instrumento no ensino-aprendizagem de inglês; o 'Code switching ${ }^{9}$ do professor universitário; o desenvolvimento da produção oral em inglês mediante as histórias; a leitura

\footnotetext{
${ }^{8} \mathrm{O}$ título da monografia "Writing reviews in English as a foreign language". A pesquisa e a elaboração da monografia foram realizadas por duas alunas: Alessandra (cujo diário reflexivo é objeto de nossa análise) e Eduarda.

9 'Code Switching' o uso de português e inglês em sala de aula.
} 
de histórias em quadrinhos para a aprendizagem de inglês; avaliação de livros didáticos de língua inglesa; música para o desenvolvimento das crianças aprendizes de inglês; o uso da tecnologia no ensino e aprendizagem da língua inglesa; ritmo e entonação em inglês.

\section{Coesão nominal e coesão verbal}

Os resultados sobre a coesão nominal e verbal nas monografias revelaram que o grupo é heterogêneo no que diz respeito ao uso desses mecanismos de textualização. Alguns alunos têm um bom domínio na utilização dos referidos mecanismos textuais. Outros, embora tenham conseguido melhorar a capacidade de usá-los depois das regulações e do tutoramento, ainda apresentam muitas dificuldades. Para o objetivo de nossa análise, selecionamos trechos das monografias de duas alunas, Liliana e Amélia, que se enquadram na segunda categoria.

No que se refere à coesão nominal, podemos observar que as alunas ainda não utilizam esse mecanismo de forma adequada, como mostram os excertos abaixo. Encontramos orações com dois sujeitos, assim como orações sem sujeito. Essa ocorrência é uma clara evidência da interferência da língua portuguesa nos textos das alunas. Vejamos nos exemplos apresentados o uso do 'sujeito oculto', um mecanismo corrente na textualidade da língua portuguesa que, todavia, não se aplica à língua inglesa. A partir dessa constatação, podemos deduzir que, mesmo em se tratando de alunas em formação inicial e no final de curso de graduação, elas ainda apresentam dificuldades no uso da textualidade da língua-alvo.

Liliana

- This practice of teaching it is still common in 21st century and this school mentioned before was not the only place that is possible to find this type of approach [...]

- [...] not all teachers have enough knowledge in English or do not know about methodologies to teach foreign language, because is possible to observe teachers of other subjects teaching English $[\ldots]$

- $\quad[. .$.$] The comic strips used it was chosen according to student's level [...]$

Amélia

- Among the skills, it was chosen reading skill to analyse the activities of Reading section [...]

- $\quad[\ldots]$ Through reading is possible to enhance vocabulary, writing and grammar [...]

- $\quad[. .$.$] And through one paragraph is easier to a student from basic level$

- [...] The first one, it was to discover how was the frequence of the students on website [...]

A partir dos exemplos abaixo, é possível verificar que Liliana e Amélia apresentam dificuldades também no uso da coesão verbal. Neste caso, o uso inadequado do referido 
mecanismo se apresenta de formas variadas. A título de ilustração, temos a forma incompleta do verbo no infinitivo sem a preposição 'to', como em 'if students like or not read'. Isso reflete a interferência da língua portuguesa pelo fato de o verbo no infinitivo não ser precedido de nenhuma partícula.

Outra forma inapropriada da coesão verbal é a não concordância em número observada nos textos, como em 'results... was quantified' ou 'the use of language become more conscious. Além desses exemplos, elencamos também o uso de verbos no particípio passado como 'fallen' em vez do simple past 'fell'; o uso inapropriado dos tempos verbais como a junção do auxiliar will do futuro simples com um verbo no particípio passado em 'the student will answered 6o question' e forma progressiva de uma ação no passado que não se aplica no exemplo selecionado: 'comics were gradually being removed'. Além desses exemplos, encontramos formas verbais no gerúndio quando este não se aplica e formas no infinitivo que deveriam estar no gerúndio (terminação com -ing).

\section{Liliana}

- [...] to know if students like or not read in English.

- $\quad[. .$.$] It is quantitative because the results of this research was quantified. [...]$

- $\quad[. .$.$] Yet if the focus of majority of the activities have been grammatical points there were questions$ whose answers students would need to infer.

- [...] Mendonça's (2010) thoughts also regarding comics and comic strip, which says that comics is a sequence of images [...]

- $\quad[. .$.$] Because of these opinions, comics were gradually being removed from schools and libraries,$ the sales drastically fallen [...]

\section{Amélia}

- However to learn a Foreign Language, besides someone be inserted in a cultural context [...] Through conscious knowledge should know the rules, grammatical structures [...]

- $\quad[\ldots]$ the use of language become more conscious. [...]

- [...] authentic tasks that follow up the text is relevant. Authentic tasks that contain links with real situation, like to read a letter and answer it, using that way the comprehension and vocabulary to writing the letter of response.[...]

- $\quad[\ldots]$ The first one is the placement test where the student will answered 60 question [...]

- We chose the levels two and three [...]. We choose draw the texts from the sublevel one from both levels $[\ldots]$

É interessante observar que os problemas de coesão verbal foram também relatados de forma explícita no diário reflexivo de outra aluna, Diana. No depoimento que segue, ela externa seu sentimento de insegurança em relação ao uso dos tempos verbais em inglês e enfatiza 'I confess that I still have doubts about them sometimes'. Ao mesmo tempo, mostra sua preocupação em querer aprimorar seu saber, que lhe daria condições de ensinar 'a forma correta'. 
Diana

"During all the course of Letras, I had some problems about verb tenses, and I confess that I still have doubts about them sometimes. It makes me reflect how can I make it better to teach my students the content correctly."

Da mesma maneira, Amélia tem consciência de que precisa desenvolver sua capacidade linguística quando explica: '/ have difficulties to develop'. Contudo, ela reflete sobre a obrigação que tem perante si mesma de adquirir confiança como profissional. Ademais, a aluna se projeta no futuro denotando a certeza de que será uma boa profissional ao dizer "/ will be a good teacher for my students."

\section{Amélia}

"About the future, I hope that I can improve my knowledge of English and some skills that I have difficulties to develop'. Thus, I should acquire confidence as a professional and, especially, grow up as person. [...] and to believe that I will be a good teacher for my students."

Os resultados relativos ao uso inadequado de coesão nominal e coesão verbal apresentados acima e, por conseguinte, a constatação de que as alunas precisam desenvolver suas capacidades linguístico-discursivas em inglês nos levam ao seguinte questionamento: como podemos esperar que as alunas/futuras professoras que apresentam problemas de escrita possam ensinar a escrita em inglês? Coadunamos com o pensamento de que "Se o professor não tomar também ele contacto com os problemas que a escrita coloca, como poderá ser capaz de explicitar aos alunos o processo de escrita?" (PEREIRA e GRAÇA, 2015).

Subjacente à argumentação e conclusão ora apresentadas, fica evidente que o ensino do gênero monografia, realizado mediante as sequências didáticas, não atingiu de forma integral os objetivos estabelecidos, na medida em que as alunas Liliana e Amélia não conseguiram ultrapassar suas dificuldades linguístico-discursivas em inglês, muito embora tenham conseguido escrever a monografia em conformidade com a infraestrutura textual do referido gênero, as sequências e os conteúdos temáticos. Na percepção de Liliana, houve melhora na sua produção escrita "I realized that my writing is a little better than in 2014 when I started my TCC for the first time. However, I need to to improve it."

Essa constatação nos leva à reflexão de que o desenvolvimento da capacidade de produção escrita na língua estrangeira não ocorre em apenas um semestre. Ao contrário, requer um trabalho de longa duração e um ensino sistemático nos diversos níveis da 
escolaridade, inclusive na universidade. Todavia, é importante ressaltar que, além do desenvolvimento observado nas capacidades linguístico-discursivas, as regulações foram acompanhadas de reflexão para o aluno tanto no momento de ensino da escrita quanto na própria aprendizagem. Acreditamos que ao ensinar a produção do gênero monografia mediante sequências didáticas e ao solicitar a escrita de um diário reflexivo, que relata a experiência de ensino e aprendizagem da escrita, ativamos uma reflexão mais abrangente sobre a percepção da formação docente inicial no que diz respeito ao ensino e aprendizagem da produção escrita e seu futuro desenvolvimento.

\section{Dos diários reflexivos}

\section{A modalização no discurso}

A partir dos trechos selecionados dos diários reflexivos, emergem alguns "topics" abrangendo tanto a questão do ensino e da aprendizagem da produção de textos escritos na língua inglesa, como a questão da formação de aprendizes de professor de língua inglesa. Esses topics evidenciam diferentes aspectos explícitos e implícitos que, a nosso ver, constituem 'elementos preocupantes' (VANHULLE, 2011).

Vejamos, nos excertos que seguem, as opiniões, as avaliações e as críticas encontradas nos discursos das alunas Alessandra e Ana Paula. Os exemplos são saturados de mecanismos de modalização.

\footnotetext{
Alessandra

"The idea of the course was good and helpful, but I believe that it came a little too late. In the first semester we had a course similar to this one but it was in Portuguese, and after having this one in English I could not help but wonder 'why didn't I see this before'? [...] throughout the graduation course we had other courses in which we had to use academic English as well and it was really difficult to do because we neither had any instruction on the language nor any feedback on our papers. So, for me, this course in the last semester adds something but not as much as it could."

Ana Paula

"I feel a little more comfortable about writing some academic genres, but as I mentioned before, It would have been better if we were exposed to these models earlier. [...] Unfortunately, we did not learned [sic] very well how to teach writing in English, since the realities of the English courses and regular schools are completely different from the academy. If I am not mistaken, we only had few lessons in one course, and they did not cover our needs as EFL teachers.
}

Em seus discursos, as alunas reclamam, questionam e fazem críticas ao currículo atual pelo fato de este não oferecer uma formação adequada no que tange à produção escrita em inglês. Alessandra externa seu espanto, que a fez questionar o sistema atual de 
formação ao dizer: "I could not help but wonder 'why didn't I see this before'?". Em seguida, reconhece sua aprendizagem, mas avalia que não foi suficiente: "this course in the last semester adds something but not as much as it could". Por sua vez, Ana Paula é mais enfática na sua avaliação de sua formação quando afirma: "It would have been better if we were exposed to these models earlier", denotando seu descontentamento em relação ao momento de ensino e aprendizagem.

Os exemplos acima evidenciam também outras questões. Em primeiro lugar, a necessidade de ajustes no currículo do curso em questão, haja vista que, no depoimento de Alessandra, quando explica: "we neither had any instruction on the language nor any feedback on our papers", fica clara a ausência de ensino da produção escrita e do feedaback sobre os textos produzidos pelos alunos ao longo do curso. Em segundo lugar, está o fato de a formação inicial não contemplar o ensino da produção de gêneros escritos na língua estrangeira, como mostra Ana Paula: "Unfortunately, we did not learned [sic] very well how to teach writing in English [...] we only had few lessons in one course, and they did not cover our needs as EFL teachers". Assim, sem os saberes necessários sobre o ensino da escrita, como pode o futuro professor ensinar textos escritos?

Em suma, o discurso das alunas, mediante os modalizadores, revela que além de suas avaliações sobre a própria capacidade de produção escrita, elas levantam vários questionamentos, permeados de inquietações sobre o atual sistema de ensino da produção de textos escritos na língua estrangeira, bem como a formação inicial do professor de línguas.

\section{Dos relatórios de estágios}

\section{Conteúdo temático}

O relatório de estágio diz muito sobre as representações que o estagiário faz do seu trabalho, do próprio sistema de ensino e da relação da escola com a universidade. Enquanto objeto de estudo, o relatório é visto como um gênero produzido na esfera acadêmica, uma ferramenta semiótica complexa que mediatiza as ações dos envolvidos na interação didática; um texto produzido por um estudante do Curso de Letras; um espaço de interação entre professor e estagiário, universidade e escola; uma avaliação importante no final do Curso; um espaço de reconfiguração do agir professoral. 
Ao produzir o seu relatório de estágio de regência, o estudante faz opções, pois não há espaço para tudo descrever e analisar. O resultado dessas escolhas, de certa forma, mostra o que de mais relevante foi para o estagiário nessa etapa de sua formação inicial. Da mesma forma, nós também selecionamos exemplos dos conteúdos temáticos para este artigo em função do espaço que dispomos. Elegemos, portanto, os seguintes temas: a interrupção das aulas, a prática de leitura, a atividade de produção escrita e a problemática do uso do livro didático em sala de aula. É sobre esses conteúdos temáticos que passamos a tratar.

A interrupção das aulas é um tema bastante polêmico. No universo dos cinquenta relatórios, 60\% dos estudantes dizem não concordar com a entrada de pessoas em sala de aula para dar informações. O fato é que na maioria das vezes, a aula termina sem que o professor tenha condições de concluir seu trabalho. Se, para o professor experiente, é difícil continuar a aula, para um estagiário é muito mais complexo. No exemplo que vemos a seguir, foi o que aconteceu:

(...) em seguida, o professor passou uma atividade para que os alunos respondessem e entregassem ao final da aula. Neste intervalo, o diretor foi dar um aviso sobre uma festa que aconteceria em dias próximos na escola. Depois de algum tempo a aula acabou. (relatório 21- grifo nosso)

Neste exemplo, nós temos a descrição feita pelo estagiário-observador. Segundo ele, entre o espaço em que foi solicitada atividade e a chegada do diretor da escola, não houve tempo para a aula acontecer. Isso nos dá margens para, pelo menos, fazer duas grandes perguntas: que condições de trabalho tem o estagiário? Qual é o papel do estagiário na escola e como ele é visto nesse espaço?

Outro conteúdo bastante presente no relatório de regência é a aula de leitura. Ele é muito presente nos relatórios, ora para informar que a aula de leitura não acontece conforme deveria ser, ora porque cada vez mais o espaço dela dá lugar a outras atividades. $\mathrm{Na}$ cena que elegemos para tratar dessa questão, o estagiário demonstra ter saberes necessários para uma aula produtiva de leitura, mas no processo da transposição didática demonstra equívocos importantes, como vimos nessa cena:

Pedimos para um aluno ler o texto "Quem vai salvar a vida", uma história com sequência dialogal predominante, mas que também havia a presença de uma outra sequência, a narrativa (relatório 13 - grifo nosso) 
Ao considerar a descrição das cenas dessa aula, chamamos atenção a questões específicas do ensino da leitura e da concepção de leitura veiculados nesse momento. No relatório, observamos que o estudante utilizou apenas a estratégia "leitura em voz alta, seguida da atividade". Esse modelo de aula de leitura é o mais corrente, conforme mostram os demais relatórios analisados, muito embora seja o mais distante de uma aula interativa de leitura, quando só realizamos esse tipo de estratégia.

A aula de leitura precisa ser planejada e esse planejamento deve dar conta de desenvolver as capacidades de linguagem (SCHNEUWLY e DOLZ, 2004) do leitor, de forma a trabalhar as muitas possibilidades de entradas no texto (LEUROUIN e KATAOKA, 2013; LEURQUIN, 2014).

Nesse exemplo, constatamos equívocos grandes e importantes em torno da aula de leitura que carecem de esclarecimentos. O primeiro está relacionado à confusão feita em torno do conceito de sequências textuais e gêneros textuais; não são sinônimos. Infelizmente são conceitos ainda não bem compreendidos, nem mesmo por muitos estudantes. O segundo equívoco diz respeito à modelização desse gênero aula de leitura. Ela não pode se limitar a atividades que tratem apenas do plano do texto, tampouco apenas dos conteúdos temáticos mobilizados nele. O último equívoco se refere à aula de língua portuguesa. Dar aula de uma língua, utilizando textos diversos em formas diversas de gêneros, e não dar espaço para o leitor compreender a gramática e seu movimento no texto em prol da comunicação pode minimizar a compreensão do ensino e aprendizagem de línguas e o papel da linguagem nas relações humanas.

As pontuações que fazemos implicam em uma mudança de atitude, de compreensão sobre a própria aula de leitura. Para nós, o texto possibilita mobilizar no leitor emoções. $\mathrm{Na}$ sala de aula de língua, devemos estudar o texto de maneira a entender como os elementos linguístico-discursivos se organizam textualizando essas emoções; podemos estudar como os conteúdos temáticos estabelecem relações entre si. Acreditamos que, neste caso, a atividade de leitura pode levar o leitor ao mundo imaginário, mas ela também pode contribuir para que o estudante amplie seus conhecimentos e possa intervir no mundo, utilizando a língua em outros espaços linguageiros e de forma consciente.

O terceiro conteúdo selecionado pelo estudante foi a produção escrita. A primeira constatação que fizemos diz respeito à relação feita entre leitura e produção de texto. Vimos que sempre que há uma aula de leitura, ela termina com uma produção de texto. 
Essa relação parece muito complexa por muitas razões e citamos duas delas: diante do tempo limitado para trabalhar as duas atividades, uma delas é comprometida. Normalmente é a produção de texto. A segunda razão diz respeito à própria dependência que se estabelece entre as duas atividades; a produção escrita não é a última etapa da aula de leitura.

A professora pediu aos alunos para lerem anúncios publicitários. Pediu para eles recortarem anúncios e colarem em uma cartolina. Em seguida, mostrou alguns vídeos de anúncios. Depois pediu para os alunos escreverem no caderno um anúncio. (relatório 37 )

É importante registar que em nenhum relatório foi constatada uma referência ao processo do ensino da escrita.

O quarto conteúdo temático selecionado é o uso do livro didático em sala de aula. Desde o Programa Nacional do Livro Didático, a qualidade do livro melhorou bastante. Todos os estudantes recebem o livro didático. Quanto ao uso dele, conforme relatos escritos, há conflitos que se instalam em sala de aula. Há situações em que o aluno o leva para a sala de aula, mas que ele não é utilizado; há outras em que o professor copia os exercícios, apesar de os alunos estarem com os livros. O fato é que, conforme o estagiário:

Reclamando mais uma vez que os alunos não trouxessem os livros para a sala, uma grande discussão acabara acontecendo. Os alunos argumentavam que trazem os livros, mas que a professora nunca os utiliza, mas apenas as cópias de textos que ela mesma traz. Uma grande gritaria acontece na sala com quase todos os alunos defendendo uma o estudante que afirmava não trazer o livro pelo fato de este ser pesado demais para ser carregado para uma aula que nem mesmo o utilizará.

(relatório 34 - grifo nosso)

Nessa cena, o estudante demonstra preocupação com o problema que ocorreu na sala de aula. Essas cenas nos remetem a dois pontos impossiveis de serem desconsiderados: o conteúdo e a forma. No tocante ao conteúdo temático, temos a problemática do uso do livro didático em sala. Primeiro, queremos destacar a dependência que se instaura em sala de aula. Muitas vezes, há uma mudança de papel, de maneira que o professor, ao adotar o livro, delega ao autor do material a sua função de mediador no processo de ensino e aprendizagem. Isso gera um problema porque se, por um lado, o livro didático pode contribuir positivamente para a aula, por outro lado, quando utilizado de forma passiva, contribui negativamente para o bom resultado no ensino e aprendizagem porque o 
professor passa a ser um mero observador e não atua como mediador da aprendizagem e do desenvolvimento.

O segundo ponto diz respeito a como estudante sai da universidade se comunicando através da escrita, como veremos na sessão que segue.

\section{Dos relatórios de estágios}

\section{Coesão verbal}

Como afirmamos ao longo de nossas reflexões, os conteúdos descritos nos relatórios dão acesso ao que os estudantes acreditam ser importantes no período do estágio de regência. Mas a forma como estão escritos esses conteúdos fornece indícios para que possamos ter acesso a outra realidade, aos saberes a ensinar em uso pelo próprio estudante. Nesse contexto, definimos a coesão verbal como um importante ponto a ser refletido.

Em nossos relatórios de estágio, há muitos problemas no âmbito da coesão verbal que certamente implicam a própria compreensão do texto. No último exemplo dado, o estudante fez a opção correta pelo tempo passado, mas ao longo de sua descrição não atenta às relações necessárias que deveria estabelecer entre os verbos, como observamos nas partes sublinhadas e em negrito.

Assim sendo, quando deveria utilizar um pretérito perfeito do indicativo, ele optou pelo pretérito perfeito do subjuntivo, comprometendo diretamente a compreensão da informação, ocasionando incoerências na interação/comunicação. Da mesma maneira, observamos uma inadequação com relação ao uso do mais que perfeito ao invés do pretérito perfeito (Reclamando mais uma vez [por] que os alunos não trouxessem os livros para a sala, uma grande discussão acabara acontecendo). Na sequência da descrição, há um uso do presente do indicativo onde esperávamos o uso do pretérito imperfeito (Os alunos argumentavam que trazem os livros, mas que a professora nunca os utiliza, mas apenas as cópias de textos que ela mesma traz). Esse conjunto de equívocos proporciona ao leitor dúvidas quanto aos acontecimentos, insegurança quanto às informações.

\section{Dos autocomentários}

Hoje, o autocomentário tem um papel muito importante na formação inicial do professor porque o aluno em formação pode verbalizar situações às quais, antigamente, o 
pesquisador não tinha acesso. As ações observáveis eram vistas, descritas e analisadas pelo estagiário e as não observáveis eram apresentadas em forma de hipóteses.

Em uma situação de grupo focal, ao questionar sobre a importância da produção do relatório, o estudante se posiciona da seguinte maneira:

a produção do relatório é um momento de avaliação... crescimento ... reflexão pessoal e profissional dos estudantes que fazem é durante o relato das aulas observadas e ministradas que temos uma visão geral... desde o planejamento das aulas a sua prática em sala, expomos nossos planos de aulas e atividades propostas e verificamos como foi posto em prática... se deu certo tudo o que foi planejado e quando não saí exatamente como planejado, nesse momento vemos o que pode ser feito para melhorar a execução. (autocomentário 15)

A despeito do fato de constituir apenas um exemplo, a posição acima verbalizada representa um percentual elevado de estudantes que veem de maneira positiva a prática da produção escrita do relatório. Nessa fala, há pelo menos dois pontos que merecem destaque. O primeiro ponto a ressaltar diz respeito ao fato de que o estudante diz perceber o processo da escrita do relatório como uma atividade de reflexão sobre a profissão. 0 segundo ponto a destacar diz respeito à confiabilidade dos autocomentários, uma vez que neles o estagiário afirma desenvolver uma reflexão sobre a formação inicial, mas no relatório de estágio apenas descreve as cenas.

\section{Para concluir}

As duas cenas apresentadas neste artigo, muito embora retratem contextos distintos, revelam convergências no que diz respeito à produção escrita de gêneros acadêmicos e à formação inicial do professor.

As capacidades linguístico-discursivas observadas, tanto na monografia quanto no relatório, nos levam a questionar o que podemos esperar do futuro professor diante de evidências de práticas sedimentadas. Se o estudante em formação apresenta problemas no uso da linguagem, como podemos esperar que ele ensine a língua?

A expectativa do professor-pesquisador consiste em ler e analisar as cenas de aula de estágio observando os pontos sobressalientes relacionados com a prática docente. Todavia, nós nos deparamos com problema de ordem linguístico-discursiva observado na escrita do relatório. Reflexão essa que nos permite inferir que eles precisam desenvolver sua capacidade de linguagem. 
Ao analisar a questão da formação do professor a partir dos conteúdos temáticos contidos nos relatórios, observamos que muito embora o aluno descreva suas experiências em sala de aula, ele não apresenta uma reflexão colocando-se também como profissional da área de docência e como agente do processo e aprendizagem.

Por fim, salientamos que os resultados aqui apresentados, seguramente, anunciam um alerta para a necessidade de refletirmos sobre a questão da escrita do gênero acadêmico e, por conseguinte, a formação inicial docente, sobretudo porque a mesma problemática já foi apontada por outros pesquisadores: Botelho e Leurquin (2011) com foco na Universidade Federal do Maranhão e Rodrigues (2002) que analisou relatórios produzidos por concluintes de universidades públicas das cinco regiões brasileiras.

Diante dos resultados apresentados neste artigo e de outros evidenciados por pesquisas realizadas há pelo menos quinze anos, não seria o momento de repensarmos o perfil linguístico do aluno que estamos formando?

\section{Referências}

ALLAL, L. Régulations des apprentissages: orientations conceptuelles pour la recherche et la pratique en éducation. In: ALLAL, L.; MOTTIER LOPEZ, L. (Dir.). Régulation des apprentissages en situation scolaire et en formation. Bruxelles: De Boeck, 2007. p. 7-23.

Impliquer l'apprenant dans les processus d'évaluation: promesses et pièges de I'autoévaluation. In: DEVOPER, C.; NOËL, B. (Ed.). L'évaluation des compétences et des processus cognitifs, modèles, pratiques et contextes. Bruxelles: De Boeck, 1999. p. 35-56.

ASSIS, J. Ações do professor e do universitário nas práticas de ensino e de aprendizagem da escrita acadêmica: o papel da avaliação e da reescrita no processo de apropriação do gênero resenha.

Revista

Eutomia, http://www.repositorios.ufpe.br/revistas/index.php/EUTOMIA/issue/view/34/sho, v. 1. Universidade Federal de Pernambuco, dezembro, Recife, 2014.

BOTELHO, J. L.; LEURQUIN, E. V. L. F. Nível de letramento de professor de língua portuguesa em formação e situação de interação através do gênero acadêmico relatório. In: LEURQUIN, E. V. L. F.; BEZERRA, J. R. M.; SOARES, M. E. (org). Gênero, Ensino e formação de professor Campinas: Mercado de Letras, 2011, p. 11-17.

BRONCKART, J-P. Qu'est ce que le développement humain? Interrogations, impasses et perspectives de clarifications. In: FRIEDRICH, J.; HOFSTETTER, R.; SCHNEUWLY, B. (dir.). 
Une science du développement est-elle possible? Controverses du début du XXe siècle. Rennes: Presses Universitaires de Rennes, 2013, p.207-226.

Atividade de linguagem, textos e discursos: por um interacionismo sociodiscursivo. Tradução Anna Raquel Machado, Péricles Cunha. São Paulo: EDUC, 1999.

CHEVALLARD, Y. La transposition didactique du savoir savant au savoir enseigné. Grenoble: La Pensée Sauvage, 1991.

DOLZ, J.; NOVERRAZ, M.; SCHNEUWLY, B. Sequências didáticas para o oral e a escrita: apresentação de um procedimento. In: SCHNEUWLY, B.; DOLZ, J. Gêneros orais e escritos na escola. Tradução Rojo, R.; Cordeiro, S. G. Campinas: Mercado de Letras, 2004, p. 95-128.

DOLZ, J.; GAGNON, R.; DECÂNDIO, F. Produção escrita e dificuldades de aprendizagem. Tradução: Decândio, F.; Machado, A. R. São Paulo: Mercado de Letras, 2010.

DOLZ, J.; GAGNON, R.; TOULOU, S. Production écrite et difficultés d'apprentissage. zème ed. Genève: Université de Genève, 2009. (Carnets des Sciences de l'Éducation)

FRIEDRICH, J. Lev Vygotski: médiation, apprentissage et développement: une lecture philosophique et épistémologique. Genève: Université de Genève, 2010. (Carnets des Sciences de l'Éducation)

FRIEDRICH, J.; HOFSTETTER, R.; SCHNEUWLY, B. (dir.). Une science du développement estelle possible? Controverses du début $d u X X$ X siècle. Rennes: Presses Universitaires de Rennes, 2013

HOFSTETTER, R.; SCHNEUWLY, B. (Ed.). Savoirs en transformation: au coeur des professions de l'enseignement et de la formation. Bruxelles: De Boeck, 2009.

KLEIMAN, A. B. A formação do professor: retrospectivas e perspectivas na pesquisa. In: KLEIMAN, A. B. A formação do professor. Campinas: Mercado de Letras, 2008, p. 13-38.

LEUROUIN, E. V. L. F. O espaço da Leitura e da escrita em situação de ensino e de aprendizagem de português língua estrangeira. Revista Eutomia, http://www.repositorios.ufpe.br/revistas/index.php/EUTOMIA/issue/view/34/sho, v. 1. Universidade Federal de Pernambuco, dezembro, Recife, 2014.

LEUROUIN, E. V. L. F; KATAOKA, M. A aula de leitura através do olhar do futuro professor. Revista Científica da faculdade Lourenço Filho, V. 9, Fortaleza, 2013.

PARAHYBA, F. D. Como lidar com a (Re)Escrita na Língua Estrangeira? In: Congresso Internacional da Abralin, 6., 2009, João Pessoa. Anais... João Pessoa: Ed. Idéia, 2009.

Narrativa do professor: um meio de repensar a prática docente. In: MOURA, V.; DAMIANOVIC, M. C.; LEAL, V. (Org.). O ensino de línguas: concepções e práticas universitárias. Recife: Ed. da UFPE, 2010. p. 263-277. 
PEREIRA, L. A; GRAÇA, L. Formação dos Professores para o ensino da produção de textos escritos: possíveis e impossíveis. In: LEURQUIN, E; COUTINHO, M. A.; MIRANDA, F (Org.) Formação docente: textos, teorias e práticas. Campinas: Mercado de Letras, 2015, p. 55-74.

PERRENOUD AEBI, C. Enseigner l'écriture: paroles d'enseignants. (Cahiers des Sciences de I'Éducation, 84). Genève: Université de Genève, 1997.

RODRIGUES, M. G. S. A Organização do Relatório de Prática de Ensino de Língua Portuguesa: um perfil textual do concluinte de Letras. Tese de doutorado. UFPE, 2002.

SCHNEUWLY, B. L'objet enseigné. In: SCHNEUWLY, B.; DOLZ, J. Des objets enseignés en classe de français. Rennes: Presses Universitaires de Rennes, 2009. p. 17-28.

. Vygotski, l'école et l'écriture. (Cahiers des Sciences de I'Éducation, 118) Genève: Université de Genève, 2008.

SCHNEUWLY, B.; DOLZ, J. Des objets enseignés en classe de français. Rennes: Presses Universitaires de Rennes, 2009.

. Gêneros orais e escritos na escola. Tradução: Rojo, R.; Cordeiro, S. G. Campinas: Mercado de Letras, 2004.

VANHULLE, S. Comprendre le développement professionnel par l'analyse des discours. SCRIPTA, Belo Horizonte, v. 15, n. 28, 2011, p. 145-169.

Savoirs professionnels et construction sociodiscursive de l'agir. VALS-ASLA: Bulletin Association Suisse de Linguistique Appliquée, n. 90, 2009. p.167-188.

VYGOTSKI, L. S. A construção do pensamento e da linguagem. Tradução Paulo Bezerra. São Paulo: Martins Fontes, 2009.

. Le problème de l'enseignement et du développement mental à I'âge scolaire. In: SCHNEUWLY, B.; BRONCKART, J. P. (Dir.). Vygotski aujourd'hui. Neuchâtel: Delachaux et Niestlé, 1985. p. 95-117. 
' Fatiha Dechicha PARAHYBA - Departamento de Letras da Universidade Federal de Pernambuco (UFPE), professora doutora em Linguística. Pesquisadora nas áreas de Ensino e Aprendizagem da língua inglesa, Formação de Professor e Estudos Tradutórios, dechichaparahyba@gmail.com

ii Eulália LEUROUIN - Departamento de Letras Vernáculas da Universidade Federal do Ceará (UFC), professora doutora em Educação. Pesquisadora nas áreas de Ensino e Aprendizagem de Português língua materna e língua estrangeira e de Formação de Professor, eulaliaufc@gmail.com

Recebido em 30/06/2015 Aceito em 29/07/2015 